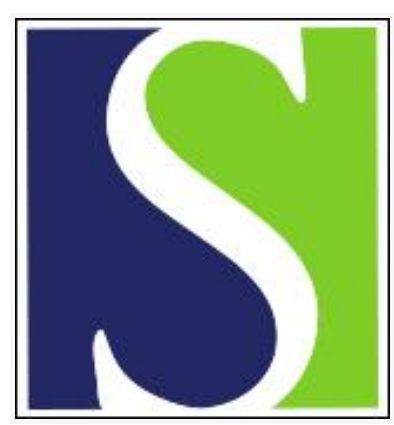

Scand J Work Environ Health 1979;5(2):158-161

https://doi.org/10.5271/sjweh.2656

Issue date: Jun 1979

Styrene and styrene oxide concentrations in the air during the lamination process in the reinforced plastics industry. by Pfäffli $P$, Vainio $H$, Hesso A

Key terms: air; lamination process; reinforced plastics; reinforced plastics industry; styrene; styrene oxide; styrene oxide concentration

This article in PubMed: www.ncbi.nlm.nih.gov/pubmed/472687

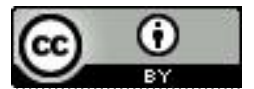




\title{
Styrene and styrene oxide concentrations in the air during the lamination process in the reinforced plastics industry
}

\author{
by PIRKKO PFÄFFLI, M.Sc., HARRI VAINIO, M.D., and ANTTI HESSO, M.Sc. ${ }^{1}$
}

\begin{abstract}
PFÄFl, P., VAINIO, H. and HESSO, A. Styrene and styrene oxide concentrations in the air during the lamination process in the reinforced plastics industry. Scand. $j$. work environ. \& health 5 (1979) 158-161. Styrene and styrene oxide concentrations were measured during the lamination process in the reinforced plastics industry. The mean concentration of styrene in the personal samples was $130 \mathrm{ppm}$, the highest value measured being $350 \mathrm{ppm}$. The average concentration for styrene oxide alone was $0.1 \mathrm{ppm}$, whereas the corresponding measurement for styrene oxide and its decomposition products combined was $0.7 \mathrm{ppm}$. In comparison then, the concentrations of styrene oxide and its derivatives were much lower (about $0.5 \%$ of the total) than those of styrene.
\end{abstract}

Key words: reinforced plastics, styrene, styrene oxide.

Workers involved in the processing of unsaturated polyester resins have shown an increased rate of chromosomal aberrations in their peripheral lymphocytes as compared to a control group $(1,4,5)$. When large articles such as boats and car parts are produced, the exposure to styrene is the most abundant and is accompanied by smaller exposures to other compounds, such as acetone, peroxides or alkylphosphates. In a recent paper (1) the presence of styrene oxide was also emphasized. This compound, which is also a metabolic intermediate of styrene, has been shown to be mutagenic and clastogenic (3, 7). For this reason we determined the presence of styrene, styrene oxide, and possible styrene

1 Department of Industrial Hygiene and Toxicology, Institute of Occupational Health, Helsinki, Finland.

Reprint requests to: Ms. Pirkko Pfäffli, Institute of Occupational Health, Haartmaninkatu 1, SF-00290 Helsinki 29, Finland. oxide derivatives during the production of polyester resin glass-fiber laminates.

\section{MATERIALS AND METHODS}

The samples for this study were collected in two factories producing boats, car parts and building materials.

The lamination methods used in the process were hand lay-up application and spray application. The resin used was preaccelerated polyester resin dissolved in styrene monomer. The polymerization was completed with the addition of hardener to the resin, either acetylacetone peroxide or methyl ethyl ketone peroxide (as trialkylphosphate solution). The amount of hardener needed was from 1 to $2 \%$ for hand lay-up application and from 5 to $6 \%$ during spray application. 


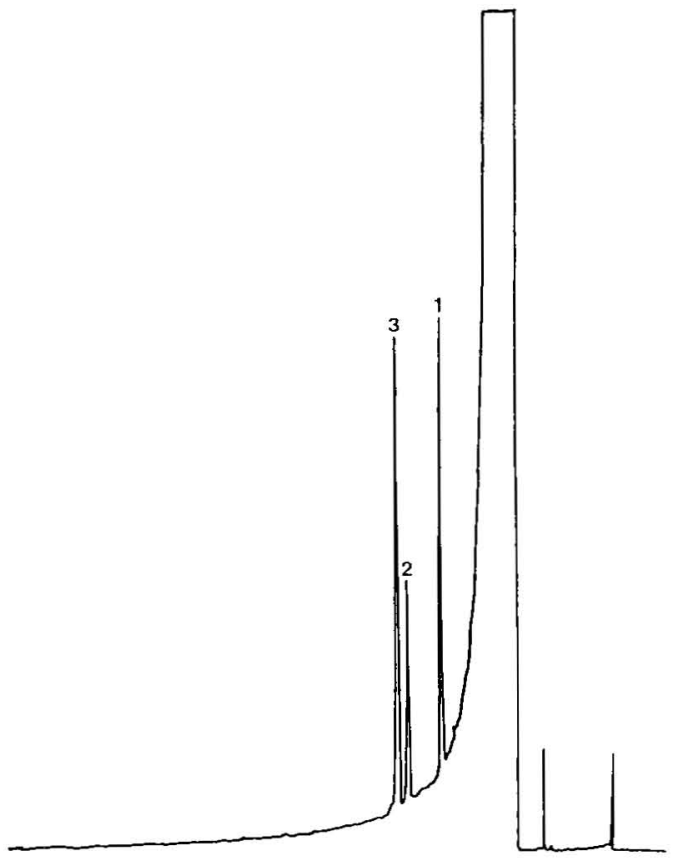

Fig. 1. A chromatographic curve of styrene oxide and its derived compounds. The chromatographic conditions were: gas chromatograph: Hewlett-Packard $5720 \mathrm{~A}$; column: SP 1000, 50 $\mathrm{m}$, inner diameter 0.762 ("macrocapillary," Separation Research Lid., Finland), temperature $140^{\prime \prime} \mathrm{C}$; carrier gas: helium at a flow rate of $7 \mathrm{ml} / \mathrm{min}$; injection: splitless, temperature $180^{\prime} \mathrm{C}$; detector: flame ionization, temperature 180 C. $(1=$ benzaldehyde, $2=$ styrene oxide, 3 $=$ acetophenone)

The personal and ambient air samples were collected consecutively by means of the charcoal tube sampling method (2) during the active workday. The sampling time varied from 60 to $120 \mathrm{~min}$. The samples were eluted from the charcoal with dichloromethane immediately after the sampling and assayed by capillary gas chromatography. The details of the chromatographic arrangements are presented in fig. 1.

The combined coefficients of variation for the elution and analysis were between 2.5 and $3.5 \%(\mathrm{~N}=6)$ for each compound when analyzed from sampling tubes made for test purposes in the laboratory. These test charcoal tubes contained the same mixture at the same concentration level ( $0.01 \mu \mathrm{g}$ of compound/tube) as those tubes of the actual samples, which were taken from the workplace.

The external standards for the analysis contained the same kind and amount of reactivated coconut charcoal in the dichloromethane solution (PCB, Chemviron Ltd., Pittsburgh, U.K.) as that used in the sampling tubes.

The qualitative identification of styrene, styrene oxide and derived compounds in the dichloromethane eluate was made with a mass spectrometer (Varian MAT $112 \mathrm{~S}$ ), which was coupled to a capillary gas chromatograph (Aerograph 1400) and a data system (Varian MAT SS 166). The details for the mass spectrometry are given in fig. 2, which presents the total ion detection of a mass spectrum.

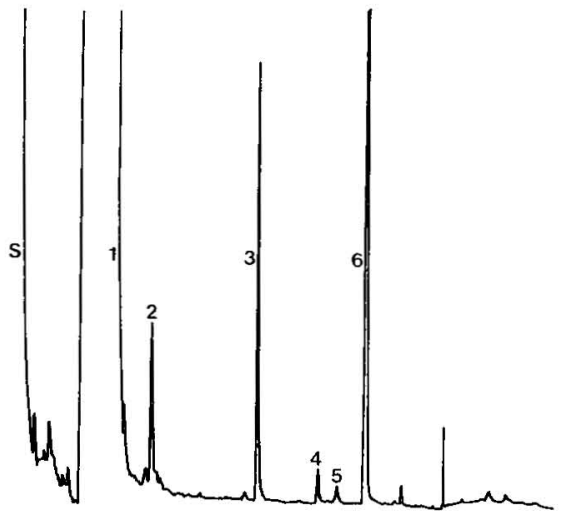

Fig. 2. The total ion curve of the mass spectrum of dichloromethane eluate from a charcoal tube sample collected from the air during polyester resin application. The curve was analyzed on a Triton X-305 glass capillary with an open slit coupling $(35 \mathrm{~m}$, inner diameter $0.35 \mathrm{~mm}$ ). The carrier gas was helium at a flow rate of $1.5 \mathrm{ml} / \mathrm{min}$, and the column temperature was programmed from $60^{\circ}$ to $180^{\prime \prime}$ $\mathrm{C}$ with $81 / \mathrm{min}$ intervals. Detection was made with an EI/EID source with a source temperature of $240^{\prime} \mathrm{C}$ and the electron energy at $80 \mathrm{eV}$. (1 = styrene, $\quad 2$ = $u$-methylstyrene, 3 - benzaldehyde, $4=$ styrene oxide, $5=$ acetophenone, 6 - triethylphosphate) 
Table. 1. Concentrations of styrene, styrene oxide, and styrene oxide derivatives in the air during the lamination of polyester resins with fiber glass by hand lay-up and spray application. The means \pm the standard deviations are given.

\begin{tabular}{|c|c|c|c|c|c|c|}
\hline Type of sample & $\mathrm{N}$ & $\begin{array}{c}\text { Styrene } \\
\text { oxide } \\
\text { (ppm) }\end{array}$ & $\begin{array}{l}\text { Aceto- } \\
\text { phenone } \\
\text { (ppm) }\end{array}$ & $\begin{array}{l}\text { Benz- } \\
\text { aldehyde } \\
\text { (ppm) }\end{array}$ & $\begin{array}{c}\Sigma^{a} \\
(\mathrm{ppm})\end{array}$ & $\begin{array}{c}\text { Styrene } \\
\text { (ppm) }\end{array}$ \\
\hline \multicolumn{7}{|c|}{ Hand-lay-up application } \\
\hline Personal & 29 & $0.04 \pm 0.02$ & $0.05 \pm 0.03$ & $0.30 \pm 0.16$ & 0.39 & $132.9 \pm 109.6$ \\
\hline Ambient air & 5 & $0.04 \pm 0.02$ & $0.05 \pm 0.03$ & $0.28 \pm 0.22$ & 0.37 & $58.9 \pm 69.5$ \\
\hline \multicolumn{7}{|l|}{ Spray application } \\
\hline Personal & 8 & $0.12 \pm 0.07$ & $0.47 \pm 0.10$ & $0.48 \pm 0.25$ & 1.07 & $130.2 \pm 68.8$ \\
\hline Ambient air & 4 & $0.17 \pm 0.19$ & $0.39 \pm 0.38$ & $0.67 \pm 0.77$ & 1.23 & $114.9 \pm 114.1$ \\
\hline
\end{tabular}

a $\quad I=$ additive value of styrene oxide and its derivatives.

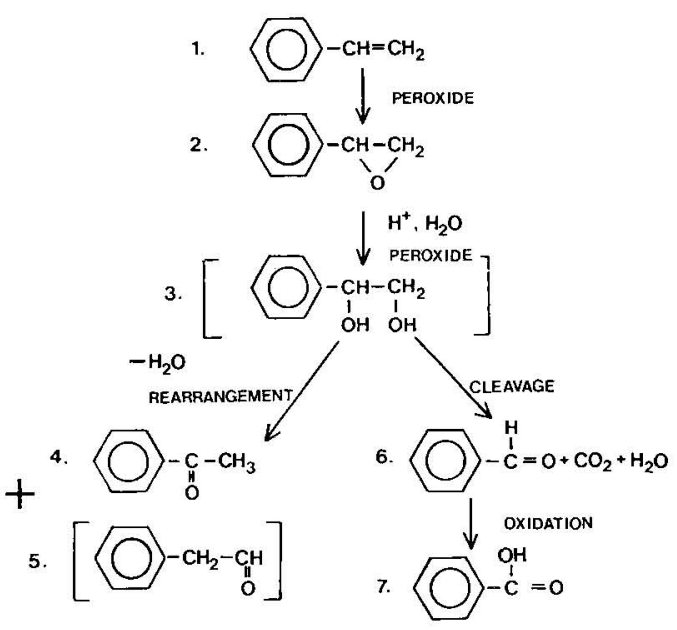

Fig. 3. The probable oxidation route of the vinyl group of styrene. $(1=$ styrene, $2=$ styrene oxide, $3=$ phenylglycol, $4=$ acetophenone, $5=$ phenylacetaldehyde, $6=$ benzaldehyde, $7=$ benzoic acid)

\section{RESULTS AND DISCUSSION}

The mean styrene concentration in the personal air samples was $132 \mathrm{ppm}\left(\mathrm{cm}^{3} / \mathrm{m}^{3}\right)$ (range 28-349 ppm) for both of the polyester resin application methods used (table 1). The ambient air samples from the hand lay-up and spray applications showed lower concentrations, i.e., 59 and $115 \mathrm{ppm}$, respectively.

Styrene can be converted to styrene oxide (phenylethyleneoxide) in the presence of organic peroxides and even air (6). The mean styrene oxide concentrations in the personal samples were $0.04 \mathrm{ppm}$ (range from 0.02 to $0.10 \mathrm{ppm}$ ) for the hand layup procedure and $0.12 \mathrm{ppm}$ (range from 0.05 to $0.24 \mathrm{ppm}$ ) for the spray technique. The mean concentrations of styrene oxide in the surrounding air were 0.04 and 0.17 ppm, respectively.

Styrene oxide is, however, an unstable compound in the presence of peroxides and air (6). It is easily converted further into other oxidized products (fig. 3). As styrene oxide derivatives, we found acetophenone and benzaldehyde (fig. 1 and 2). Theoretically it should also be possible to find phenylacetaldehyde and benzoic acid, which is the oxidized product of benzaldehyde. However, we suspect the concentrations of these products to be very low because we could not detect them. Neither did we find the intermediate phenylglycol, which is probably very unstable in the presence of peroxides.

The mean acetophenone concentrations of the personal and ambient air samples were 0.05 and $0.05 \mathrm{ppm}$, respectively, during the hand lay-up method and 0.47 and $0.39 \mathrm{ppm}$, respectively, during the spray technique. The corresponding mean benzaldehyde concentrations were 0.30 and $0.28 \mathrm{ppm}$ during the hand lay-up method and 0.48 and $0.67 \mathrm{ppm}$ for the spray technique.

The mean additive concentration of oxidized products (styrene oxide, acetophenone and benzaldehyde) was $0.39 \mathrm{ppm}$ in the personal samples $(0.37 \mathrm{ppm}$ in the ambient air samples) during hand lay-up application and $1.07 \mathrm{ppm}(1.23 \mathrm{ppm}$ in the ambient air samples) during spray application. 
In conclusion it can be said that a minor amount of styrene is converted to styrene oxide in the presence of peroxides when unsaturated polyester resins are processed. Styrene oxide is an unstable compound which is easily converted further into more stable acetophenone and benzaldehyde. The concentrations of these compounds seemed to depend slightly on the type of processing (on different amounts of peroxides present). The concentrations of these oxidized compounds were, however, so small in the air samples that they appear to have a negligible importance as far as the hygienic aspects of the lamination process are concerned. Thus it appears evident that it is the styrene itself, and not the styrene oxide, which has the greatest importance when the potential health hazards of the reinforced plastics industry are being evaluated.

\section{ACKNOWLEDGMENTS}

We wish to thank Ms. Raija Vaaranrinta and Mr. Yrjö Peltonen for their skillful technical assistance.
This study was supported with a grant (241 A-C/77) from the Swedish WorkEnvironment Fund.

\section{REFERENCES}

1. FLEIG, I. and THIESS, A.M. Mutagenicity study of workers employed in the styrene and polystyrene processing and manufacturing industry. Scand j. work environ. \& health 4 (1978): suppl. 2, 254-258.

2. KALLIOKOSKI, $P$. and PFÄFFLI, P. Charcoal sampling method for determining the concentration of styrene in air. Scand. j. work environ. \& health 1 (1975) 193-198.

3. LINNAINMAA, K., MERETOJA, T., SORSA, M. and VAINIO, H. Cytogenetic effects of styrene and styrene oxide. Mutat. res. 58 (1978) 277 - 286.

4. MERETOJA, T., JÄRVENTAUS, H., SORSA, $M$. and VAINIO, H. Chromosome aberrations in lymphocytes of workers exposed to styrene. Scand. j. work environ. \& health 4 (1978): suppl. 2, 259-264.

5. MERETOJA, T., VAINIO, H., SORSA, M. and HÄRKÓNEN, H. Occupational styrene exposure and chromosomal aberrations. Mutat. res. 56 (1977) 193-197.

6. MORRISON, R.T. and BOYD, R.N. Organic chemistry. Allyn and Bacon Inc., Boston, MA 1975 , pp. 207-208 \& 562.

7. VAINIO, H., PÄAKKKÖNEN, R., RÖNNHOLM, K., RAUNIO, V. and PELKONEN, O. A study on the mutagenic activity of styrene and styrene oxide. Scand. j. work environ. \& health 3 (1976) 147-151. 